\title{
An Investigation of Third Generation (3G) Mobile Technologies and Services
}

\author{
Heikki Karjaluoto \\ University of Oulu \\ E-Mail: heikki.karjaluoto@oulu.fi
}

\begin{abstract}
The objective of this paper is to evaluate the underlying paradigms of third generation (3G) mobile services. Given the success of second generation (2G) mobile communications systems and services, the third generation mobile networks and applications are faced with a lot of expectations such as providing ubiquitous access to online services via mobile terminals. However, 3G technologies and applications have encountered obstacles that have hindered both the technology development and user acceptance. This paper reviews existing literature related to $3 G$ and develops a framework that presents the factors that contribute to the success of 3G. The findings provide insight into the development and marketing of 3G services.
\end{abstract}

Keywords: 3G, User Acceptance, Mobile Communications, Telecommunications

\section{INTRODUCTION}

Many studies have investigated the success factors and user acceptance of the third generation (3G) mobile network and its services. In search of the so-called killer applications of $3 G$ networks, researchers have often argued that there will be no killer application(s) as there were in 2G (e.g., Mallick, 2003: 7), or at least that future killer applications are simply unknown (Lehrer, 2004). However, this question should not be answered without an explicit definition of what is meant by killer applications and how the successful services will be evaluated. Generally speaking, a killer application can be defined as an application that surpasses all other competing applications. Moreover, it inspires users to purchase it and eventually corners the market. The question of how to evaluate killer applications is difficult. Whether it should be done in terms of transactional revenue, subscription or airtime remains an open question (e.g., Ralph, 2002). Looking back at the so-called killer applications of the $2 G$ network, we can 
undoubtedly concur that text messaging, i.e. the short message service (SMS), followed by ring tones and logo downloads are the killer applications of $2 \mathrm{G}$ and 2,5G networks (e.g., Buellingen \& Woerter, 2004; Kumar, 2004; Liang \& Wei, 2004). This raises the question of whether these or related services will continue to dominate the $3 \mathrm{G}$ market, or will new mobile services emerge.

Third generation mobile telephony protocols support higher data rates, measured in kbps (kilobits per second) or Mbps (megabits per second), intended for applications other than voice-centric. The shift from $2 G$ to $3 G$ not only gives users fresh ways to communicate but also a variety of new services such as browsing the Internet, e-mail, instant messaging, video-conferencing and digital television. 3G also makes guidance, presence, and location-based services available to mobile users (e.g., Chevillat \& Schott, 2003). In addition, current features of mobile phones such as cameras and personal time management systems are expected to develop. Since 2001 3G trials across the world have shown that the main development from $2 \mathrm{G}$ and 2,5G to $3 \mathrm{G}$ is faster connection speed (Robins, 2003), referring to wider bandwidth. The main characteristics of $3 \mathrm{G}$ are to provide mobile multimedia services at a transmission rate of $144 \mathrm{kbps}$ at the high speed, $384 \mathrm{kbps}$ at the speed of walking and 2Mbps indoors (Mohr \& Konhäuser, 2000; TDSCDMA Forum, 2004). This theoretical maximum (2Mbps) is close to the speed of LAN connections that many households nowadays have. In addition, 3G networks can offer faster data transmission than the slowest LAN connection (256kbps), and GPRS (General Packet Radio Service) that usually offers transfer speed of 40 kbps (Birchler, Smyth, Martinez, \& Baker, 2003) to 55 kbps (Sonera, 2004a).

Figure 1 shows the various technologies related to $3 G$ and their suitability for mobile users. Beyond 3G, it is predicted that mobile networks and the wireless communication landscape will be based on various technologies, offering seamless mobility with cellular networks (Frodigh, 2001; Honkasalo, Pehkonen, Niemi, \& Leino, 2002; Hurel, Lerouge, Evci, \& Gui, 2003; Wisely \& Mitjana, 2003). Fourth generation (4G) services will enable broadband wireless communication at home, at the office and on the move. In other words, new networks will make the services provided by the Web and the Internet as well as a variety of other services such as multimedia and entertainment available to mobile users (Chevillat \& Schott, 2003). 


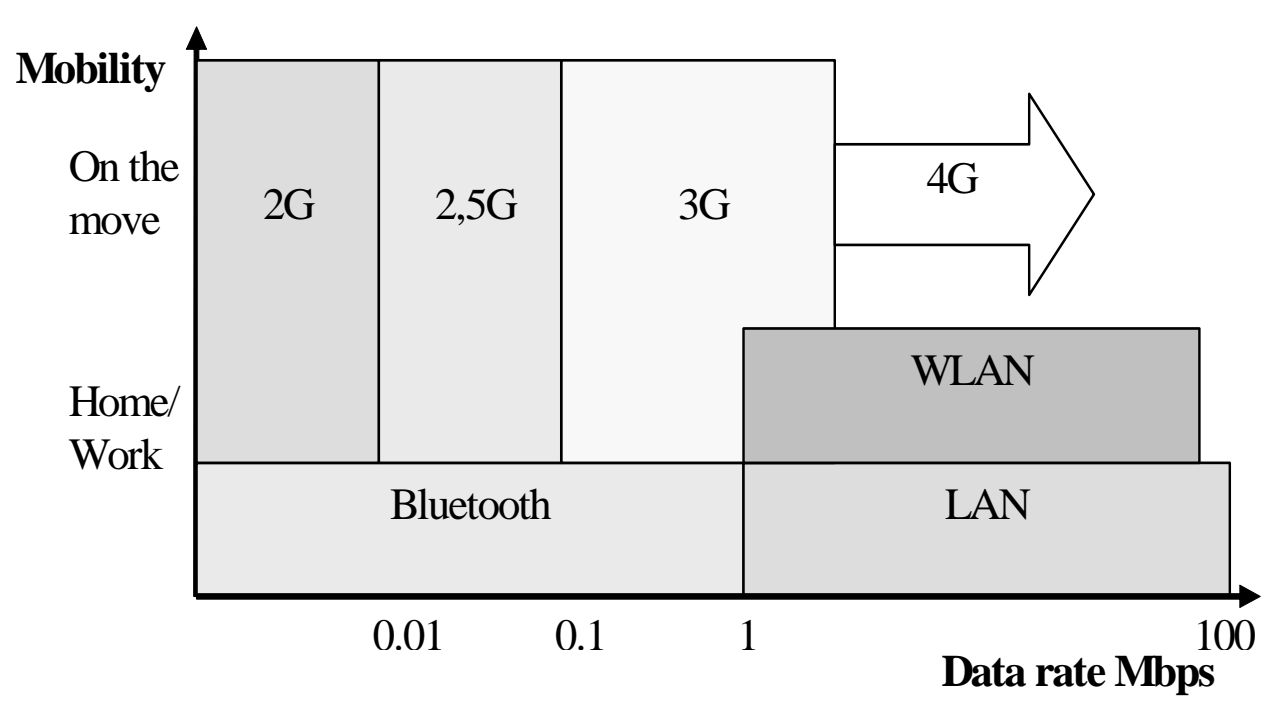

Figure 1 Classification of Mobile Networks and Mobility

The objective of the paper is to discuss $3 G$ networks and services from a marketing perspective. The discussion is organized so that we first emphasize the importance of the antecedents of 3G's success by outlining the underlying factors namely standardization, user acceptance, and pricing, which are among the influential factors affecting the development and marketing of successful 3G services (e.g., Fenton, Moss, Lock, Bloomfield, Fisher, Pratt, Brookland, \& Gil, 2001; Goodrick \& Srivastava, 2002). This will be followed by a discussion of the main $3 G$ services and their ability to attract new subscribers and satisfy their needs with acceptable prices. To conclude, a discussion of the implications of the findings, the study's limitations, and possible topics for further research will be presented.

\section{ANTECEDENTS OF THE SUCCESS OF 3G SERVICES}

\section{Industry Standards}

The importance of common industry standards with 3G networks has been emphasized in many studies (see e.g., Curwen, 2000; Grundström \& Wilkinson, 2004; Harrison \& Holley, 2001; Kumar, 2004). The mobile phone industry is currently using many standards [e.g. Japanese PDC (Personal Digital Communication), European GSM, American CDMA], which has made it difficult for users traveling to utilize their phones worldwide. The evolution of $3 G$ is expected to simplify this because in Europe there are only two standards competing; the WCDMA (Wideband Code Division Multiple Access) which will become the European UMTS (Universal Mobile Telecommunications System) and the CDMA2000 (Code Division Multiple Access). Although the WCDMA and the CDMA2000 are regarded as the two main standards (MobileIN, 2004) in the world, there 
are other variants of 3G such as NTT DoCoMo's Freedom of Mobile Multimedia Access (FOMA) and the Chinese TD-SCDMA (Time Division-Synchronous Code Division Multiple Access), which are also competing for market share. As the TD-SCDMA developed by Siemens and its Chinese partners has suffered technical problems it is not to date ready for commercialization (Hillman, 2004). The WCDMA standard is said to dominate the global market for the next five years (Sehovic, 2003). However, 3G networks still require large investment efforts in for example in base stations, in order to provide promised transfer speeds (Robins, 2003). With standardization it is possible to meet one of the basic goals of 3G; to provide global access for the same services. This means creating a truly single, worldwide standard. The International Telecommunication Union (ITU) is working on 3G international standardization through its project IMT-2000 (International Mobile Telecommunications) that aims at setting the global standard for 3G. Thus, it is expected that in the coming years we will have a worldwide standard for 3G.

\section{User Acceptance}

Before discussing the applications and services related to $3 G$ networks, it is important to consider user acceptance of 3G services and to classify different user needs. Generally speaking, in designing 3G applications and planning profitable business models, the end-users' needs and wants should be in the hot spot (e.g., Fenton et al., 2001; Gerstheimer \& Lupp, 2004). The main challenge when exploring user needs and wants lies in the intersection of unknown future customers' needs and wants and new technology that is not even available for many users. Therefore, it is suggested that service developers can only meet the needs and wants with a profound understanding of the mobile communication system, ranging from voice-centric services to multimediacentric services (Gerstheimer \& Lupp, 2004). Furthermore, their study suggests that an interpretative-creative approach should be used when designing $3 G$ services rather than taking linear or analytic problem solving approaches. Therefore designers should examine users' needs and requirements, with concrete reference to situation-oriented and social-spatial contexts; concentrating on open parameters like 'user', 'place', 'process', and 'time' (Figge, 2004; Gerstheimer \& Lupp, 2004).

To get the big picture, it is essential to understand the different situations in which consumers and business users use mobile services. First, we can distinguish the different types of presence people typically have. Presence can be broadly defined as reachability, availability, and willingness to communicate with other users. Presence is one of the central factors in designing mobile services (Camarillo \& Garcia-Martin, 2004: 303). Presence data includes information about whether users are online or not, if they are idle or busy, and various other information users have given to the presence service such as information about their communication means and capabilities concerning their mobile terminals, for example. At a basic level, presence information can be classified to at home, at work and mobile (on the move) (Dholakia \& Dholakia, 2004). To begin with, at home users are typically connected with at least two types of networks. More and more 
households have fixed Internet access (LAN) that allows relatively fast Internet connection speed (starting from $256 \mathrm{kbps}$ ). Thus, it is expected that households with fixed Internet access will use mobile devices (classified in this paper as phones and PDAs, but excluding laptops) differently than households without fixed Internet access. For instance, mobile terminals can be used to get online access, either directly from mobile terminal or in connection with another terminal such as laptop or PC. With the help of 3G, mobile terminals as mentioned can offer faster connection speeds than some LAN connections. However, with the diffusion of $3 \mathrm{G}$ networks, we should expect $3 \mathrm{G}$ phones to be used in combination with personal computers. For example, many mobile operators in Europe (e.g. Vodafone, Orange, T-Mobile, O2) already offer 3G data cards that allow fast access to Internet services via laptops, and are able to utilize also GPRS connection when $3 G$ is not available (ZDNet UK, 2004). The idea is that data cards provide a broadband wireless link to the Internet or company network (like WLAN) allowing users to do the same computer activities on the road as in the office.

At work, users typically also have fixed Internet access that is used to access many informative services related to work. However, more people are relying on mobile terminals to manage their daily activities. With the diffusion of smart phones, computers and mobile terminals are more and more used in combination. As smart phones can be synchronized with laptops and table computers, followed by their ability to send and receive e-mails and use of other company related services, the line between different terminals is faded.

The third option, mobile, means that the services users can access are limited due to network constraints. On the go users mainly rely on mobile networks that to date offer limited data transmission speeds, although the rise of the $3 G$ network and Wireless Local Area networks (WLAN) provide faster data transmission. The most important development in relation to mobile users and the services they need relate to the networks' ability to provide the same services globally. As mobile users are increasingly traveling worldwide, it is important to develop networks and services that can be accessed with one mobile terminal. This has been mentioned as one of the main challenges mobile network development will face in the coming years (e.g., Birchler et al., 2003). In conclusion, mobile data services undoubtedly have the most value for users on the go, or for users who are not currently able to access the services the Internet provides via other means such as fixed Internet connection (LAN) or wireless local area network (WLAN).

\section{Pricing}

Pricing of the $3 G$ services is definitely one of the biggest challenges facing telecommunication companies (e.g., Buellingen \& Woerter, 2004; Fenton et al., 2001). Setting the right price for service usage is difficult. Private use of mobile data services is heavily dependent upon pricing issues. Multimedia centric services (e.g. MMS), for example, has suffered around the world (excluding Asia) from high pricing policy. Although many mobile operators are offering discounts for MMS services such as 
sending multimedia messages for free during weekends (Sonera, 2004b), they have not yet reached the mobile operators' expectations. Mobile operators have used two types of pricing policies in offering mobile data services (Lindemann, Lohmann, \& Thuemmler, 2003). First, pricing can be based on a fixed price, also called flat-rate pricing (Geng \& Whinston, 2001), typically ranging from 15-25€ per month in Europe. With fixed pricing operators usually offer 100Mbps transfers per month. This means that a user can send and receive normal sized documents (e.g. Powerpoint presentations) 50 times per month. As usage exceeds $100 \mathrm{Mbps}$ in a month, the price increases often dramatically. Fixed pricing is the most common pricing strategy for mobile data services (Lindemann et al., 2003). Usage based pricing (or dynamic pricing) regulates usage by imposing a fee based on the amount of data send and received. In addition, as shown in Lindgren, Jedbratt \& Svensson (2002: 181), users seem to be prepared to pay for mobile services, but only to the services they actually use, as opposed to fixed monthly subscriptions. Although fixed pricing from users viewpoint has many advantages, mobile operators have had to control data transmission to avoid overcapacity in certain times (e.g. during evenings). This relates to the fact that the more users are accessing the network at the same time, meaning the transmission speed is slower.

\section{A LOOK AT 3G SERVICES -IS THERE ANYTHING NEW?}

In general terms, 3G services comprise of wide bandwidth services such as enhanced communication (e.g. messaging, e-mail, video), browsing the Web (Robins, 2003; Symbian Glossary, 2004), and location-specific information (Barnes, 2002) like informing users about the availability of stores, restaurants, gas stations, free parking lots and so on near them (Kanter, 2003). In addition, business users will have a direct access to company networks while traveling or working outside office. From marketing point of view, identifying and designing these services and setting an appropriate price is said to be the core marketing task related to 3G (Robins, 2003). Although it can be concluded that the most successful 3G services probably belong to one of these categories, it is impossible to predict in detail exactly what is going to happen in the mobile marketplace. However, we will not experience a so-called radical innovation in the market; merely the evolution of existing mobile communications giving users faster transmission speeds which then might open up possibilities for new mobile data services also. Next, we will go through the most common mobile data services and ponder their ability to serve as the most successful 3G services.

\section{Mobile Internet -Browsing the Web from Mobile}

A wide range of authors from various disciplines ranging from technology to business have argued that the $3 \mathrm{G}$ will enable mobile access to the Internet (e.g., Barnes, 2003: 13; Dziong, Khan, Medepalli, \& Nanda, 2002; Harmer \& Friel, 2001), or in other words, aim to merge cellular networks and the Internet meaning that mobile users can have ubiquitous access to all the services that the Internet provides from messaging to 
browsing (Camarillo \& Garcia-Martin, 2004: 5). The term mobile Internet, or Internet in mobile, refers to gaining access to the Internet using a handheld, wireless device like a mobile phone or PDA. As $2 \mathrm{G}$ networks have been mainly voice-centric with low data transmission capacity (Harmer \& Friel, 2001), 2,5G and 3G will speed up data transmission speeds. However, in $3 G$ networks the data transmission speed is depended upon the number of users accessing the network at the same point of time. Thus, in reality $3 G$ networks rarely offer the theoretical maximum speed. Another question relates to the users need to browse the Web from mobile. Besides the most used mobile Internet services in 2,5G, namely news and entertainment (Buellingen \& Worter, 2004), the question of whether there are any other online services that are preferably used from mobile rather than from other devices such as laptops which have larger screens and also easier to use interfaces with large keyboards, remains open. However, the question of whether users are willing to browse the Internet from mobile phone or PDA becomes unimportant as terminals are only devices, and finally the user judges the terminals and chooses the one he or she prefers. For instance, by using $3 \mathrm{G}$ data card users can browse the Internet via their laptop or via a mobile device. The purpose of use dictates the terminal in the end.

Research has suggested that the most attractive WAP applications are news, entertainment, ticketing and reservations, as well as banking (Buellingen \& Worter, 2004). These are actually among the most common online services used with computers as well (e.g. Karjaluoto, Mattila, Pento, 2002). To conclude, while many 3G services are operated via the Internet, browsing the Internet from mobile phones or PDAs will not be a mobile version of fixed-line access (Lindgren, Jedbratt, \& Svensson, 2002: 4). In fact, people do not use the Internet in the same way from mobile terminals as they do when accessing the Internet via larger screens from computers. France Telecom Research \& Development (2004) predicts that mobile Internet offers the advantage of always being near at hand, and of being a personal tool. On this basis possible successful services might be services developed for traveling purposes like ticketing, checking schedules, traffic reports and related services.

\section{E-mail services}

E-mail service was rated as the number one preferred mobile service by the Swedes in 2001 (Lindgren, Jedbratt, \& Svensson, 2002: 180), followed by banking and use of encyclopedia. E-mail services can be categorized into Web-style HTML e-mail services and plain text e-mail services. HTML e-mail services provide more flexibility with the format and appearance while plain text e-mail comprises of a letter-style message (AMA, 2004). Although e-mail has become a widely accepted and accessible communications medium during the recent years (e.g. Hahn, 1998), there is lack of research about the use of e-mail from mobile devices. For many Internet users, both private and business users, e-mail has been the most common way of exchanging information, documents, and communication (Cho, Byun \& Sung, 2003). Although e-mail is cheap, easy to access and 
is asynchronous in nature (Cho, Byun \& Sung, 2003), e-mail services have suffered from the receipt of unsolicited messages or even spam. The fear of receiving unsolicited messages and spam on mobile devices may slow the adoption of e-mail services among mobile users. Secondly, as the first mobile virus news has been reported in media (BBC News, 2003), mobile users might want to protect their mobile devices by avoiding using e-mail services.

\section{Messaging services}

Mobile messaging, referring to short message service (SMS) and multimedia message service (MMS), is expected to be the most utilized mobile service in the future. It is estimated that step-by-step consumers as well as business users will upgrade their messaging from sending simple text messages to multimedia messages including pictures and video clips (e.g., Hurel et al., 2003; Sigurdson \& Ericsson, 2003). Although 3G networks will make bandwidth hungry services such as sending, receiving, and downloading video clips possible (e.g., Rainisto, 2004), there are notable cultural differences in adopting multimedia messaging services. For example, while the European market has not adopted multimedia messaging to large extent, due to various reasons such as pricing policy and relatively complex usage, Asians have eagerly adopted MMS (e.g., Sigurdson \& Ericsson, 2003). On average, while a typical user in Europe sends one to two MMS messages per month, an Asian takes and sends 20-30 MMS messages.

Besides SMS and MMS services, instant messaging (IM) on the Internet is one of the most popular services especially among youngsters (Camarillo \& Garcia-Martin, 2004: 331). The instant messaging service has the potential to be utilized widely among mobile users as the service allows users to send content (e.g. a text message, html page, a picture, a file containing a song, a video clip, or other file) to another user in near-real time (Camarillo \& Garcia-Martin, 2004: 331). This instant messaging service is combined with presence service, giving the possibility to see if other users are available and reachable.

The framework shown in Figure 2 summarizes the discussion of this paper. This framework, based on a review of prior research and industry reports, should provide impetus for future work in the area that identifies in more detail the critical issues, also beyond the presented. 
Underlying factors

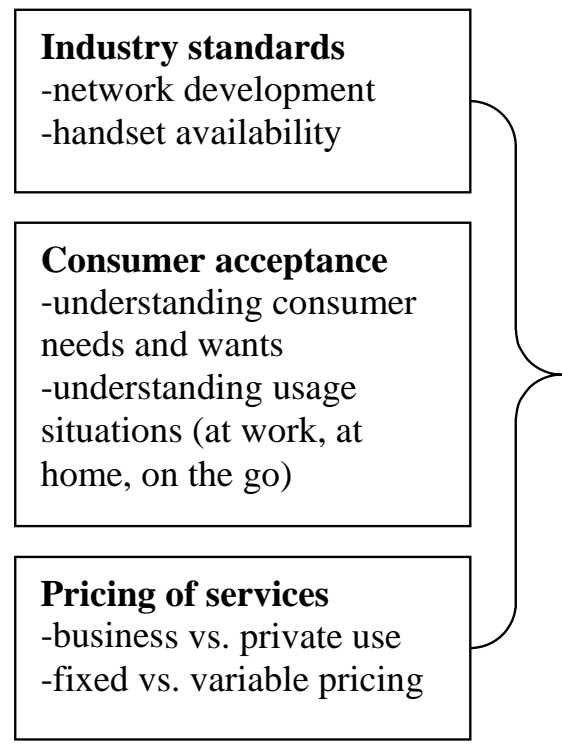

$3 G$ services

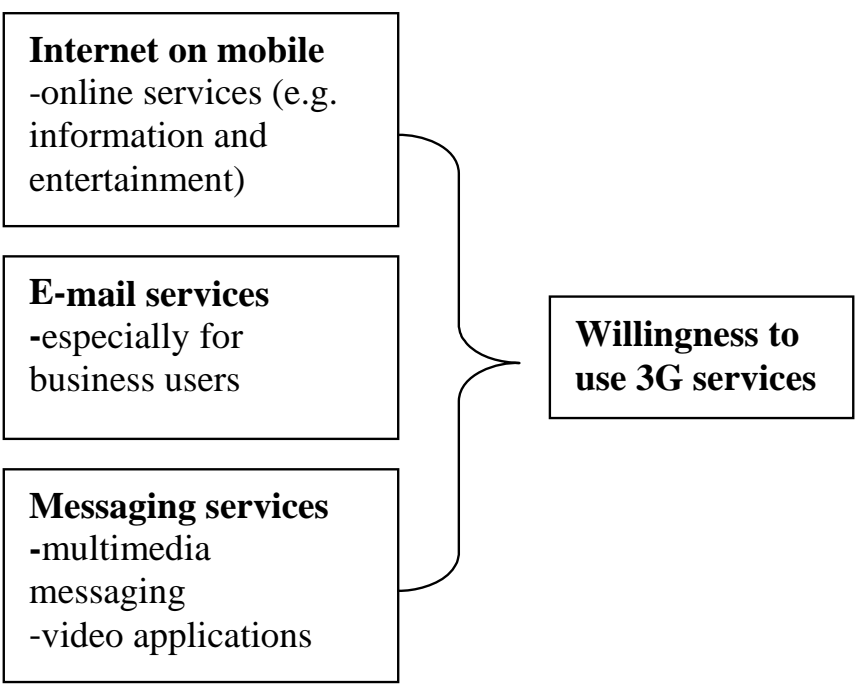

Figure 2 Hypothetical Model of 3G Acceptance

\section{CONCLUSION}

Today, the majority of mobile services used via 3G networks are already available in current 2,5G networks (GPRS, EDGE) such as browsing the Web, sending and receiving multimedia messages (like pictures and video), and e-mailing. Therefore, 3G should not be viewed as a new technology surpassing the existing 2,5G networks, or a revolution in mobile communication. Instead, 3G should be considered to be evolution of existing mobile communications (Harmer, 2003). In the light of the discussion in this paper, there is strong evidence to suggest that the main outcome of using 3G networks and services will be to get access to the same services with faster data connection speed. Furthermore, it seems that the success of $3 G$ lies in its ability to serve not only mobile users but in providing access to the Internet with data cards inserted in laptops. Thus, 3G networks will serve the same purpose as LAN and WLAN networks.

In terms of business opportunities, telecommunication companies' main source of income is still coming from voice-centric services. For example, the mobile operator Hutchinson, offering services purely in 3G networks, announced this autumn 2004 that its main source of income comes from discount packets that offer free speech time in $3 G$ networks. Moreover, as long as the price of the network time is high in 3G, operators cannot wait fast diffusion of data centric mobile services. According to mobile operators, 
$3 G$ is needed in congested places where the demand on current mobile networks exceeds the capacity.

Another important factor affecting future of $3 G$ is the availability of reasonably priced handsets. 3G devices launched to the market during 2004 have also suffered from various problems such as high power consumption that limits usage time.

The findings presented should be interpreted in the light of certain limitations. The results are based on existing material found from various sources and thus concern the development of $3 \mathrm{G}$ globally. Future studies should concentrate on country specific research to provide a more detailed understanding of the phenomenon at hand. Another limitation concerns the framework developed. Willingness to use 3G services is definitely dependent on various other factors beyond the framework presented, which could not all be addressed within this study.

On this basis, future research that identifies additional factors or views the factors presented in different light would contribute to the understanding of $3 \mathrm{G}$ acceptance. Thus, a natural extension of this study is the collection of primary data about the use and acceptance of $3 \mathrm{G}$ services in both consumer and business markets.

\section{Acknowledgements}

The financial support of the Finnish Funding Agency for Technology and Innovation is gratefully acknowledged.

\section{REFERENCES}

American Marketing Association. 2004. Dictionary of marketing terms. http://www.marketingpower.com/mg-dictionary.php. Accessed Nov. 30, 2004.

Barnes, S. J. 2002. The mobile commerce value chain: analysis and future developments. International Journal of Information Management, 22, 91-108.

Barnes, S. J. 2003. mBusiness: The strategic implications of wireless technologies. Oxford, UK: Elsevier, Butterworth-Heinemann.

BBC News. 2003. Mobile virus threat looms large. http://news.bbc.co.uk/2/hi/ technology/2690253.stm. Accessed Dec. 29, 2004.

Birchler, M., Smyth, P. P., Martinez, G., \& Baker, M. 2003. Future of mobile and wireless communications. BT Technology Journal, 21 (3), 11-21.

Buellingen, F., \& Woerter, M. 2004. Development perspectives, firm strategies and applications in mobile commerce. Journal of Business Research, 57 (12), 14021408. 
Camarillo, G., \& Garcia-Martin, M. A. 2004. The 3G IP multimedia subsystem (IMS): Merging the Internet and the cellular worlds. Chichester, West Sussex, UK: John Wiley \& Sons.

Chevillat, P. R., \& Schott, W. 2003. Broadband radio LANs and the evolution of wireless beyond 3G. IBM Journal of Research and Development, 47 (2/3), 327-336.

Cho, S., Byun, J. - H., \& Sung, M. 2003. Impact of the high-speed Internet on user behaviors: case study in Korea. Internet Research: Electronic Networking Applications and Policy, 13 (1), 49-60.

Curwen, P. 2000. Next generation mobile: 2,5G or 3G? Journal of Policy, Regulation and Strategy for Telecommunications, 2 (5), 455-476.

Dholakia, R. R., \& Dholakia, N. 2004. Mobility and markets: emerging outlines of mcommerce. Journal of Business Research, 57 (12), 1391-1396.

Dziong, Z., Khan, F., Medepalli, K., \& Nanda, S. 2002. Wireless Internet access using IS-2000 third generation system: a performance and capacity study. Wireless Networks, 8 (4), 325-336.

Fenton, C. J., Moss, J. G. O., Lock, D. W., Bloomfield, R., Fisher, J. F., Pratt, D. M., Brookland, A., \& Gil, J. 2001. 3G trials and developments. BT Technology Journal, 19 (1), 127-137.

Figge, S. 2004. Situation-dependent services - a challenge for mobile network operators. Journal of Business Research, 57 (12), 1416-1422.

France Telecom R\&D. 2004. UMTS: the era of mobile multimedia. http://www.rd.francetelecom.com/en/technologies/ddm200401/dossier.php.

Accessed Dec. 3, 2004.

Frodigh, M. 2001. Future generation wireless networks. IEEE

Transactions on Personal Communications, 8 (5), 10-17.

Geng, X., \& Whinston, A. B. 2001. Profiting from value-added wireless services. IEEE Computer, 34, 87-89.

Gerstheimer, O., \& Lupp, C. 2004. Needs versus technology-the challenge to design third-generation mobile applications. Journal of Business Research, 57 (12), 1409-1415.

Goodrick, J., \& Srivastava, L. 2002. Licensing of third generation (3G) mobile. Journal of Policy, Regulation and Strategy for Telecommunications, 4 (1), 48-55.

Grundström, C., \& Wilkinson, I. F. 2004. The role of personal networks in the development of industry standards: a case study of 3G mobile telephony. The Journal of Business and Industrial Marketing, 19 (4), 283-293.

Hahn, K. 1998. Qualitative investigation of an e-mail mediated help service. 
Internet Research: Electronic Networking Applications and Policy, 8 (2), 123-135.

Harmer, J. A. 2003. Mobile multimedia services. BT Technology Journal, 21 (3), 169180.

Harmer, J. A., \& Friel, C. D. 2001. 3G products -what will the technology enable? BT Technology Journal, 19 (1), 24-31.

Harrison, F., \& Holley, K. A. 2001. The development of mobile is critically dependent on standards. BT Technology Journal, 19 (1), 32-37.

Hillman, P. 2004. Kiinan 3G-horisontti on yhtä hämärän peitossa. http://www.digitoday.fi/showPage.php?uk=1\&page_id=12\&news_id=38082. Accessed Dec. 2, 2004.

Honkasalo, H., Pehkonen, K., Niemi, M. T., \& Leino, A. T. 2002. WCDMA and WLAN for 3G and beyond. IEEE Wireless Communications, 9 (2), 14-18.

Hurel, J. - L., Lerouge, C., Evci, C., \& Gui, L. 2003. Mobile network evolution: from 3G onwards. Alcatel Technology White Paper.

Kanter, T. G. 2003. Going wireless, enabling an adaptive and extensible environment. Mobile Networks and Applications, 8 (1), 37-50.

Karjaluoto, H., Mattila, M., \& Pento, T. 2002. A study on Internet usage among bank customers in Finland. AMA Winter Marketing Educators' Conference Proceedings (Austin, Texas), 13, 422-429.

Kumar, S. 2004. Mobile communications: global trends in the 21st century. International Journal of Mobile Communications, 2 (1), 67-86.

Lehrer, M. 2004. National lead markets and the design competition for 3G network applications. Journal of Business Research, 57 (12), 1397-1401.

Liang, T. - P., \& Wei, C. - P. 2004. Introduction to the special issue: mobile commerce applications. International Journal of Electronic Commerce, 8 (3), 7-17.

Lindemann, C., Lohmann, M., \& Thummler, A. 2003. A unified approach for improving QoS and provider revenue in 3G mobile networks. Mobile Networks and Applications, 8 (3), 209-221.

Lindgren, M., Jedbratt, J., \& Svensson, E. 2002. Beyond mobile. People, communications and marketing in a mobilized world. Hampshire, UK: Palgrave.

Mallick, M. 2003. Mobile and wireless design essentials. Indianapolis, IN: Wiley.

MobileIN. 2004. 3G mobile in a minute. http://www.mobilein.com/3G.htm. Accessed Dec. 3, 2004.

Mohr, W., \& Konhäuser, W. 2000. Access network evolution beyond third generation mobile communications. IEEE Communications Magazine, 38 (12), 122-133. 
Rainisto, S. 2004. Samsung ottaa Nokian tähtäimeensä [Samsung takes Nokia in sight]. Talouselämä, 22, 22-28.

Ralph, D. T. 2002. 3G and beyond -the applications generation. BT Technology Journal, 20 (1), 22-28.

Robins, F. 2003. The marketing of 3G. Marketing Intelligence \& Planning, 21 (6), 370378.

Sehovic, A. 2003. The whole world in 3G: the right choice. http://uk.gsmbox.com/ news/mobile_news/all/95639.gsmbox. Accessed Jul. 7, 2004.

Sigurdson, J., \& Ericsson, P. 2003. New services in 3G - new business models for streaming and video. International Journal of Mobile Communications, 1 (1/2), 15-34.

Sonera. 2004a. Näin pääset 3G-maailmaan. http://www.sonera.fi/artikkeli/ 0,3398,l-fi_h11202_a-254154,00.html. Accessed Dec. 27, 2004.

Sonera. 2004b. Multimediaviestit viikonloppuisin $0 €$. http://www.sonera.fi/artikkeli/ 0,3398,l-fi_h-11203_a-254194,00.html. Accessed Dec. 29, 2004.

Symbian Glossary. 2004. http://www.symbian.com/technology/glossary.html\#h. Accessed Nov. 30, 2004.

TD-SCDMA Forum. 2004. 3G and TD-SCDMA. http://www.tdscdma-forum.org/EN/ resources/see.asp?id=12. Accessed Nov. 30, 2004.

Wisely, D. E., \& Mitjana, B. T. 2003. Evolving systems beyond 3G -the IST BRAIN and MIND projects. BT Technology Journal, 21 (3), 102-121.

ZDNet UK. 2004. The great 3G data card road test. http://insight.zdnet.co.uk/ communications/3ggprs/0,39020421,39174498,00.htm. Accessed Dec. 28, 2004. 
